\title{
AC 2009-1691: USING MOVIES TO EXPLORE ELEMENTS OF TECHNOLOGICAL LITERACY
}

\section{John Blake, Austin Peay State University}

JOHN W. BLAKE is an Associate Professor in the Department of Engineering Technology at Austin Peay State University, Clarksville, TN. He served as department chair from 1994-2005. He received his B.S., M.S., and Ph.D. in Mechanical Engineering from Northwestern University, and is a registered Professional Engineer in the State of Tennessee. 


\title{
Using Movies to Explore Elements of Technological Literacy
}

\begin{abstract}
To reach the goal of developing technological literacy among college graduates, many universities offer courses in this area. These courses should help students learn about technology and develop their ability to adapt technology to meet their needs. They should help students recognize pertinent questions about technology, and to understand and act on answers to those questions. After such a course, students should be better prepared to make decisions about technology. In current practice, different elements, such as examples from the history of technology and technology dissection labs, are used to help students develop their knowledge and abilities.
\end{abstract}

Efforts to promote technological literacy through college courses can only be successful if students will take the courses. Unless a technological literacy course is listed as a requirement, it must be such that students will choose to take it as an elective. Elements that are both educational and appealing make it more likely that students will choose to take the course. This in turn supports the goal of developing technological literacy.

For some aspects of technological literacy, movies can be used to illustrate and explore topics. The author currently uses three movies - Apollo 13, October Sky, and Forbidden Planet - to help students see aspects of technology and engineering, and to recognize the potential for both benefits and risks inherent in technology. Apollo 13 tells a story about complex engineering systems and demonstrates the challenges of making such a system work. The story includes many examples where engineers, operating under constraints, identify and solve problems. October Sky tells an autobiographical story of a group of young men who, after a long learning curve with many failures, develops the technology to make very successful small rockets. While this is a story about high school students, it reflects the perspective of an author who went on to an engineering career with NASA, and the story is a useful study for technological projects at any level. Moving to fiction and a setting in the distant future, Forbidden Planet tells a story of the enticing benefits of new technological marvels. It also explores the risks of unintended and unanticipated consequences. While these movies illustrate important topics, they are also entertaining, and the students enjoy the movies.

In a course promoting technological literacy, movies can be both educational and entertaining for students. The paper will discuss the selection and current use of these movies in the author's course, along with options to make better use of these resources and to use this element of the course to attract potential students.

Introduction

There is growing recognition of the need for people to be better informed about technology. This has led to a technological literacy movement centered in the engineering education community. As described in a National Academy of Engineering publication, Technically Speaking: Why All Americans Need to Know More About Technology, technological literacy gives people the knowledge necessary to understand, think critically about, and make informed decisions about technology. ${ }^{1}$ The report describes this as having three dimensions: "knowledge, ways of thinking and acting, and capabilities," and specifics for each of these dimensions (quoted directly from the report as follows). ${ }^{2}$ 
Knowledge

- Recognizes the pervasiveness of technology in everyday life.

- Understands basic engineering concepts and terms, such as systems, constraints, and trade-offs.

- Is familiar with the nature and limitations of the engineering design process.

- Knows some of the ways technology shapes human history and people shape technology.

- Knows that all technologies entail risk, some that can be anticipated and some that cannot.

- Appreciates that the development and use of technology involve trade-offs and a balance of costs and benefits.

- Understands that technology reflects the values and culture of society.

Ways of Thinking and Acting

- Asks pertinent questions ... regarding the benefits and risks of technologies.

- Seeks information about new technologies.

- Participates, when appropriate, in decisions about the development and use of technology.

Capabilities

- Has a range of hands-on skills....

- Can identify and fix simple mechanical or technological problems at home or work.

- Can apply basic mathematical concepts related to probability, scale, and estimation to make informed judgments about technological risks and benefits.

In addition to the National Academy document, efforts to promote technological literacy include an NSF report by Krupzcak and Ollis, ${ }^{3}$ papers such as Ollis and Pearson, ${ }^{4}$ and the formation of a technological literacy group within the American Society for Engineering Education.

Conference sessions organized by this group have attracted a number of papers on the subject and garnered significant interest. Many of these papers have focused on courses and course activities designed to teach aspects of technological literacy. In 2006, twelve courses were documented by Krupczak and Ollis. ${ }^{5}$ Their review documented different approaches to teaching technological literacy. This review shows many different approaches to teaching the subject, including the use of device dissection exercises and the use of case studies from the history of technology. Ollis has written extensively about the use of device dissection. ${ }^{6}$ Carlson uses case studies from the history of technology to explore aspects of technological literacy. ${ }^{7}$ Rose and Flowers have developed a course focusing on technology assessment. ${ }^{8}$ Some authors approach technological literacy in courses designed to meet science requirements. ${ }^{9,10}$ In 2008 , Krupczak and Ollis addressed standard models for technology courses, ${ }^{11}$ and Krupszak et al presented a framework for developing courses on engineering and technology for students who are not engineering majors. ${ }^{12}$

The author teaches a course on engineering and technological literacy, which is offered primarily for students who are not majors in the author's department. Most students have come from an online degree program in professional studies. Use of this course in the online degree program has ensured sufficient enrollment to offer the course. Students in the author's department may take the course in place of an introductory course for first year students, and this is useful for 
transfer students who must meet that course requirement but no longer need a course designed for new students. Given the nature of the course, making it more attractive and drawing a larger and more diverse group of students is desirable.

While making the course attractive and entertaining is desirable, any course materials must serve a primarily pedagogical function. Movies are created as entertainment, and are neither the factual equivalent of case studies from the history of technology nor documented examples from technological practice. Despite these limitations, movies are useful. They can be used to demonstrate aspects of technological literacy. Instructors can use a movie to lead both to more serious presentations of material and detailed discussion, or dissection, of specific examples of technology appearing in the movie. In places where the movie may be unrealistic, the instructor can point out weaknesses and correct misperceptions. Examples of unrealistic or misleading portrayals which allow one to point out misconceptions of technology may well be as valuable as realistic examples. Examples showing a lack of technological literacy in others can help students see the need for study in this area. Despite any deficiencies, the entertaining format of the movies is useful in attracting the student's attention and helping to build their interest in learning more.

Movies as Supplemental Course Materials

In the author's course, movies are currently used as supplements to traditional course materials. These materials include written notes as the online equivalent of lectures, textbook readings, and readings in National Academy of Engineering publications available online as well as the three movies. Students are expected to respond to discussion questions and answer sets of graded questions which include both short answer and essay questions. The movies are covered along with the other materials in these questions.

Three movies are currently used in this course and will be discussed in some detail here: Apollo 13 (1995), October Sky (1999), and Forbidden Planet (1956). They are assigned in the order given here. While not documentaries, two of the movies are based on real events. The other movie, Forbidden Planet, is fiction. All three movies tell stories that are relevant to technological literacy. The next sections will give a brief overview of what students are expected to learn from each movie, how this is related to the three dimensions of technological literacy, and a brief synopsis of each movie highlighting aspects used in the course. A discussion of work expected from students based on the movies follows these sections.

\section{Apollo 13}

This movie is used first and follows course material defining technology and engineering which includes discussion of social issues, physical constraints, and the engineering design process. The movie is assigned along with course materials discussing the movie and drawing attention to relevant points.

The online equivalent of course lectures are used to direct students to the following points of interest. It should be noted that the movie has value to the course that goes beyond these specific points.

1) It gives an example of technology as “... the entire system of people and organizations, knowledge, processes, and devices that go into creating and operating technological artifacts, as well as the artifacts themselves." While the focus of the movie is on 
operation, other course materials are used here to illuminate the making of the technology.

It is used to illustrate engineering systems through

1) an example of a complex engineering system - the Apollo/Saturn V,

2) how such a system is dependent on its many components and subsystems,

3) that a system can fail due to failure of a very small part of the system,

4) that, despite the best efforts of all involved, the risk of failure exists.

It also includes elements that demonstrate

5) an engineering team in action, including situations where major differences exist,

6) design within constraints (the $\mathrm{CO}_{2}$ filter problem) and the arbitrary nature of some design decisions (the existence of both square and round filter cartridges), and

7) dealing with uncertainty. Finally,

8) the story behind the Apollo program is used as an example of societal needs leading to the creation of technology.

The decision to develop the technology and go to the moon came from a need for the United States to demonstrate technological prowess in the area of rocket technology following the launch of the first artificial satellite and subsequent stunning demonstrations of rocket technology by the Soviet Union. The military applications of this technology and the perception that the United States was falling behind its competitor in the Cold War made such a demonstration necessary.

Through the online equivalent of class lecture material,, these specific items are related directly to aspects of technological literacy, including understanding of "basic engineering concepts and terms, such as systems, constraints, and trade-offs," "the nature and limitations of the engineering design process," knowledge "that all technologies entail risk, some that can be anticipated and some that cannot," and recognition that "technology involve trade-offs ...." Taken together, these are used to help students develop a basis for "thinking and acting.,"15

Detailed Synopsis Highlighting Specific Examples Used in the Course

The movie tells the story of the ill-fated Apollo moon mission where an electrical fault caused an explosion in an oxygen tank in the service module, which shut down the power generating fuel cells in the spacecraft. Fortunately, this occurred before the lunar landing, and the lunar module was available as a backup system to get the crew back to Earth. The role of the engineers in Mission Control is heroic, and the crew's survival depends on their ability to manage a series of difficult problems with the compromised systems of the spacecraft. The movie script was based on a book by one of the astronauts. ${ }^{14}$

The story offers many examples that are useful in teaching about engineering and technological literacy. Starting with the report and telemetry data showing that something was wrong with the spacecraft, the engineering team identifies and solves a multitude of problems. Initially, there are sharp differences over what to do. Once a course of action has been developed, the team faced many problems with severe constraints and a high degree of uncertainty. Also, it is apparent that the chances for success were poor; it was not clear that the team could bring the crew home. 
The story is one of improvisation. With failure of the main electrical power system, the primary crew habitat, the command module, would no longer function. The lunar module had to be pressed into service as a backup for this system. This is an example of a redundant system, admittedly a limited one, that could not perform all of the functions of the primary system. Also, the lunar module was not designed to perform that role, and questions of whether the lunar module could meet this demand added to the level of uncertainty. The command module was the only part of the system capable of bringing the astronauts back through the atmosphere, and there was further uncertainty over whether that system, once shut down due to the loss of power, could be restarted.

A major problem depicted was that of energy and electrical power. Loss of the fuel cell system limited the command module to electrical energy stored in batteries that would not be sufficient to power all systems used for the final reentry and return to Earth, let alone supplying power needed for the return from the moon to Earth orbit. Under severe constraints, the team on the ground had to work out a procedure for restarting enough of the command module systems to carry the crew back from orbit. Hard choices had to be made about what systems must be powered up and what systems must, despite their importance, be left without power. The depiction of the use of the spacecraft simulator in making these decisions and testing brings out another useful point: the limitations of calculations. Here, calculations are useful guides, but this physical replica of the actual system was seen as giving the best indication of whether or not the startup procedure would work.

Another example of improvisation appears when carbon dioxide filter elements designed for the command module must be made to work in the lunar module. Giving clear evidence that planning did not include a scenario where the lunar module would be required to support the three crew members for a long period, the design teams for the command module and the lunar module used different configurations for these filters. Now that command module filter elements had to be used in the lunar module, a square filter had to be used with a round hole. A group is given the problem of developing a means of using these filters and their design is constrained by materials available in the spacecraft. While in normal engineering practice a designer is unlikely to be limited to such an odd assortment of materials, at some level designers are constrained by available materials, and this does serve as an example of those limitations.

The issues noted so far appear directly in the movie. The movie can be used as the basis for discussion of other issues as well. The question of why the United States was spending the money to go to the moon is linked to political and social issues. This can be explored in the context of the movie. Issues of image and public support can be raised here as well. As a demonstration of American technological prowess, one can argue that it was necessary to project an image that every aspect of the mission was under control. This made trips to the moon seem routine, and contributed to a corresponding lack of public interest, as demonstrated in the movie by the reported failure of the television networks to carry a special broadcast from the spacecraft. In fact, despite the best efforts of all involved, this mission was a very risky and difficult task. The difficulties encountered in this mission had a serious impact on this image of competence, which had political and social consequences. These aspects can be used to help students recognize social and political issues in questions about technology and to recognize that risks exist. This in turn can help students react appropriately when technology fails. 


\section{October Sky}

This movie tells the story of a group of high school students who are inspired to make rockets. It is based on the autobiographical account of one member of the group, Homer Hickman, who, after his boyhood experiences building rockets, went on to an engineering career with NASA. ${ }^{16}$

Following Apollo 13 in the course, this movie gives an example of the process of developing technology. It is used in the course to show

1) the often rocky process of development including repeated examples of failure and

2) the process of learning from failure in the development of knowledge, processes, and other elements necessary for a successful technological creation.

Examples from the movie are emphasized to show

3) aspects of problem identification and problem solving

in the development process. This is done in the context of a project team. Course materials accompanying the movie highlight specific examples showing

4) the use of mathematics and scientific knowledge and

5) the need to seek out knowledge and expertise beyond that of the project team. Accompanying course materials also guide students to

6) recognize constraints due to limitations of available materials and manufacturing methods as well as knowledge.

While the story is about high school students and not engineering professionals, there are clear parallels with large scale programs where a long learning curve with many failures was required to develop the technology.

As with Apollo 13, material from this movie is linked directly to elements of technological literacy. In the area of knowledge, this serves as an example of the design and development process. It demonstrates for students the gap between recognition of something that can be done and creating the technology to actually be able to do it. Students also see that all problems cannot be anticipated and the value of learning from failures during development. This helps students develop an understanding of how technology is developed which is applicable to the area of "thinking and acting." Finally, the use of calculations to find a lost rocket demonstrates the application of "mathematical concepts ... and estimation to make informed judgments about technological risks and benefits." While the students watching the movie do not perform the calculations themselves, they are shown how this is useful. ${ }^{17}$

Detailed Synopsis Highlighting Specific Examples Used in the Course The main character, a high school student growing up in West Virginia, is inspired to build rockets, and enlists two friends and fellow students in this endeavor. His inspiration comes from the Soviet Union's success in putting the first artificial satellite into orbit. The group's first attempt to make a rocket is an unqualified failure. Their efforts after this point are of more interest in exploring technological literacy. The group picks up a new member who brings greater scientific knowledge to the group as well as specific information from a Scientific American article about how to make rockets. The group then learns that, while the article is helpful, it does not tell them enough to make a successful rocket.

From this point, the story documents a progression of failures where the team learns from their failures and gradually develops the ability to make successful small rockets. They encounter 
and, with help from others, solve problems in design, materials, and manufacturing of rockets and in formulation and fabrication of the solid propellant used in the rockets. An errant early rocket forces them to consider the safety of others and to move to a remote site for future launches.

The group is an example of a project team. The team faces constraints in materials, manufacturing methods and expertise, as well as knowledge. The team finds help from others who are more knowledgeable in these areas, including two machinists and their chemistry teacher. While this team relied on the good will of these people for help, one can draw parallels to a professional project team where people with needed expertise would be hired.

The story includes a demonstration of the use of mathematics and scientific knowledge. Initially, one rocket is lost, and a forest fire is blamed on the rocket. Calculations made by a group member offer evidence that the rocket could not have caused the fire and lead to the recovery of the missing rocket. This is a nice demonstration of the use of scientific knowledge of mechanics, along with the necessary mathematics, to solve a problem. It is also an example of an engineering calculation where exact information is not available and the calculation represents a best estimate of actual conditions. The calculations do not give an exact point of impact, but do point the team in the right direction.

The homemade rocket program described in the movie produced small rockets that were not used for any specific purpose. The path of development, however, has many parallels in stories of rocket development for military and scientific purposes. Accounts of programs to develop rockets such as the German V-2 and many American rockets include many rocket failures. As with the team in the movie, the professional teams learned from their failures and, over time, developed reliable systems. This movie tells such a story in a way that is both entertaining and informative.

\section{$\underline{\text { Forbidden Planet }}$}

The first two movies are dramatizations based on real events. This last movie, Forbidden Planet, is a fictional story set in the distant future. Where the other movies are used primarily to illustrate how technology is developed, this movie is used to highlight broader questions. This movie is viewed while students are completing assigned reading in a book by the historian David Nye, Technology Matters, which addresses questions of technology, society, and culture. ${ }^{18}$

In a chapter entitled "Sustainable Abundance or Ecological Crisis?," Nye addresses the question "does mastery of technology assure abundance?" and discusses the competing viewpoints of technological optimism and technological pessimism. ${ }^{19}$ Forbidden Planet offers fictional visions that support both viewpoints. While much of the movie shows a world of marvels, it also includes a nightmare vision where unanticipated consequences of a technological marvel lead to destruction. From these competing visions, it is expected that the student who is prone to excessive optimism will temper their optimism with appropriate caution and appreciate the concerns of others who see risks and concerns. Likewise, it is expected that the student who is prone to pessimism will better recognize the need for and benefits of technological progress. The issues and questions raised by the movie relate to aspects of "thinking and acting" about technology. 
Students should link the more extreme visions in this movie to more current, and perhaps less exciting, examples from other course readings. Another text for the course, Great Projects by James Tobin, ${ }^{20}$ tells stories of technological projects crucial to the development of the United States. Projects such as the development of the water supply system for New York City in the mid $19^{\text {th }}$ century $^{21}$ or the Tennessee Valley Authority ${ }^{22}$ clearly support an optimistic viewpoint. One story in particular, that of the ill-fated California Development Company and the uncontrolled flooding of the Imperial Valley due to the failure to include proper controls in a hastily constructed irrigation channel, ${ }^{23}$ gives a real example of negative consequences from a technological project. By tying the movie in with other course materials, it is hoped that both the optimists and the pessimists find a balance between the pursuit of benefits and the management of risks.

Detailed Synopsis Highlighting Specific Examples Used in the Course The movie is set in a world of new technological marvels, such as a spacecraft that can carry people through interstellar space. As if this interstellar spacecraft was not enough of a marvel, it lands on a planet that was home to a civilization whose technological achievements go well beyond that of human civilization. The ship has been sent to investigate the disappearance of an earlier expedition. They find two survivors, a father and his daughter who was born after that expedition left Earth. Something happened shortly after the expedition arrived, resulting in the destruction of their ship and the deaths of the other members of the expedition.

The two survivors have thrived since that time. The father has been studying the artifacts left behind by an ancient race, the Krell, and has been able to master some of their technology. He has been able to use the Krell's technology to meet their needs, wants, and desires. Except for the lack of company, life is very comfortable for the father, Dr. Morbius, and his daughter.

The character of Robby the Robot stands out as the embodiment of technological optimism. The robot was created using the technology of the vanished civilization. As a servant, the robot can do or produce anything that the humans desire. The robot is designed to be incapable of harming humans, and is a pure force for good.

While the optimistic image of technology represented by the robot prevails in the first part of the movie, there is also a mysterious and sinister force present on this planet. Over time, it becomes more powerful and destructive. The realization comes at the end that this is an unintended consequence of the Krell's advanced technology. The Krell had developed a system where their minds could draw directly on virtually unlimited power. While the intent was that the conscious mind would draw on this power constructively, the subconscious mind was also able to control this power, and used it destructively. This was the seed of destruction for the Krell. Dr. Morbius had inadvertently become capable of controlling this power and, like the Krell, this was beyond his conscious control. He could not stop himself from using this power destructively. To prevent further uncontrolled use of this power, the planet and the technological marvels there are destroyed.

Using Movies in the Course The goals given in the course syllabus for students include - a basic appreciation of technology and of the engineering profession, - a better vision of how technological progress occurs, 
- a recognition of how technological change affects the way people live, and an awareness of both the positive and negative results of that change,

- a sense of both the potentials and the limits of technological progress,

- an appreciation of the effect technology has had on the development of civilization, and

- a vision of where we can go from here.

The movies used in this course help students to attain these goals.

The movie assignments are documented in the course syllabus with deadlines for the students to have watched each movie. Movie assignments are linked to course material postings online (the equivalent of classroom lectures) and to reading assignments. Students should be able to find these at a local library or video store and should only have to purchase the movies as a last resort. After the deadline, the instructor's comments about the movies are posted as part of the course content. These comments give background information and draw attention to specific aspects of the movie. In some of the comments, links are given to sites where students can find more information.

Students are expected to make use of this material in both discussion and examination questions. Examinations include both short answer questions that merely demonstrate that the student has reviewed the material and more substantial essay questions, where students are expected to demonstrate that they have recognized important points from the movies and to make connections between topics in the movies and other course materials. Recognizing that some students may not be able to find the movies, the questions are written such that a student should be able to answer based on movie information available online and the instructor's comments.

While no formal survey has been made of students in this course, statements from students in email correspondence indicates that the students both enjoy the movies and find them useful. The students are successful with the questions, and their essay answers demonstrate that the movies have helped them understand concepts of technological literacy.

Some students seem to be intimidated when confronted with a course on engineering and technology, since major courses have a reputation for difficulty. The inclusion of movies in the course materials may help differentiate this course and make it seem less intimidating. The potential for a course to help people develop technological literacy can only be realized if they will take the course. It is unlikely that universities will add technological literacy courses to core requirements. Faculty and departments offering technological literacy courses will be dependent either on other departments choosing to add the course to their major requirements or on students taking the courses as open electives. The entertainment aspect of the movies can be used to appeal to students and attract them to the course.

In a traditional classroom course, the movies may have their greatest potential to generate interest. The notion of a "movie night" which serves as both an educational and a social event should be attractive to students. Such an event could attract attention on the campus, giving the course some positive publicity.

While the movies have been used along the lines of case studies, it is possible to link movies to specific devices. For example, Apollo 13 could be linked to a module on hydrogen fuel cell technology. Students could be directed to search for more information, building from the basic 
concept to study of proposals for hydrogen fuel cell vehicles and the infrastructure necessary to support them, and demonstration fuel cells could be used in a dissection lab.

The movies used in this course are all well made and respected; one movie guide rates all three movies $3 \frac{1}{2}$ out of 4 stars. ${ }^{24}$ They are used in a course that is offered primarily in either five or eight week accelerated terms. In a standard sixteen week term, more movies could be added. While movies of similar quality would be best, a lower quality movie could be useful as well. A movie that demonstrates a lack of understanding of technological issues could be useful in both showing aspects and promoting the importance of technological literacy. While educational aspects should be the primary consideration, a movie selected more for its entertainment value could help to make the course seem appealing to prospective students.

\section{Conclusions}

In a course promoting technological literacy, movies used as supplements to traditional course materials can be both educational and entertaining for students. Movies such as those used by the author, Apollo 13, October Sky, and Forbidden Planet, have elements that relate directly to aspects of technological literacy. Comments from students indicate that they find the movies useful and enjoyable in the course, and responses on essay questions indicate that the movies help students develop technological literacy. The appealing aspects of movies may be useful in these efforts to promote technological literacy by attracting students to take the course.

Bibliography

1. Technically Speaking - Why All Americans Need to Know More About Technology, National Academy Press, Washington, DC, 2002. ISBN 0-309-08262-5

2. Ibid, pg 17.

3. Krupczak, John, and David F. Ollis, Improving the Technological Literacy of Undergraduates - Identifying the Research Issues, National Science Foundation, 2005.

4. Ollis, David, and Greg Pearson, What is Technological Literacy and Why Does It Matter?, Paper No. 2006-695, Proceedings of the 2006 American Society for Engineering Education Annual Conference \& Exposition.

5. Krupczak, John, and David Ollis, Technological Literacy and Engineering for Non-Engineers: Lessons from Successful Courses, Paper No. 2006-744, Proceedings of the 2006 American Society for Engineering Education Annual Conference \& Exposition.

6. Ollis, David, Technological Literacy: Connecting through Context, Content, and Contraption, Proceedings of the 2005 American Society for Engineering Education Annual Conference \& Exposition.

7. Carlson, W. Bernard, Technological Literacy and Empowerment: Exemplars from the History of Technology, Paper No. 2006-1182, Proceedings of the 2006 American Society for Engineering Education Annual Conference \& Exposition.

8. Rose, Mary, and Jim Flowers, Technology Assessment: a Graduate Course to Build Decision-Making $\underline{\text { Skills, }}$ Proceedings of the 2008 American Society for Engineering Education Annual Conference and Exposition.

9. Bertsch, Vince, Technological Literacy as a Science GE Course in California's UC, CSU, and CCC Systems, Proceedings of the 2008 American Society for Engineering Education Annual Conference and Exposition.

10. Neeley, Kathyrn, W. Bernard Carlson, Sarah Pfatteicher, Bruce Seely, Douglas Kleine, and Roger Miller, Technology in Context: Integrating Technological "Literacy" with Science Requirements for Non-Majors, Proceedings of the 2008 American Society for Engineering Education Annual Conference and Exposition.

11. Krupczak, John, and David Ollis, Technology Courses for Undergraduates: Developing Standard Models, Proceedings of the 2008 American Society for Engineering Education Annual Conference and Exposition. 
12. Krupczak, John, Timothy Simpson, Vince Bertsch, Kate Disney, Elsa Garmire, Barbara Oakley, and Mary Rose, A Framework for Developing Courses on Engineering and Technology for Non-Engineers,

Proceedings of the 2008 American Society for Engineering Education Annual Conference and Exposition.

13. "Technically Speaking," pg 13.

14. Ibid, pg 17.

15. Lovell, Jim, and Jeffrey Kluger, Apollo 13, Mariner Books: Houghton-Mifflin Company, New York, 2006. ISBN-13: 978-0-618-61958-0.

16. Hickman, Homer H., Rocket Boys: A Memoir, Delta Books: Dell Publishing, New York, 1998. ISBN 0385-33321-8.

17. "Technically Speaking," pg 17.

18. Nye, David E., Technology Matters, MIT Press, Cambridge, MA, 2006. ISBN 0-262-14093-4

19. Ibid, pp 87-108.

20. Tobin, James, Great Projects: the Epic Story of the Building of America, from the Taming of the Mississippi to the Invention of the Internet, Free Press, Simon and Schuster, Inc., New York, 2001. ISBN 0-7432-1064-6

21. Ibid, pp 158-187.

22. Ibid, pp 138-153.

23. Ibid, pp 42-52.

24. Maltin, Leonard (ed), Leonard Maltin's Movie Guide: 2005 Edition, Plume: Penguin Group, 2004. ISBN $0-452-28592-5$ 